\title{
The Ecosystem Approach as a Means to Characterise Urban Green Spaces
}

\author{
Oliver GUNAWAN, Richard P. ARMITAGE and Philip JAMES \\ University of Salford, Manchester/United Kingdom·o.t.gunawan@edu.salford.ac.uk
}

This contribution was double-blind reviewed as extended abstract.

\begin{abstract}
The ecosystem approach offers new holistic perspectives regarding the services humans derive from urban green spaces. These perspectives can be used to develop a deeper understanding of urban ecosystems and improve the efficacy of urban planning and management. The conceptual spatial framework proposed here incorporates a land cover map based on multiple spectral indices derived from Landsat TM imagery, specifically to tackle difficulties in distinguishing land cover within the urban environment. The framework facilitates a novel conceptualisation of multiple ecosystem service performance considering unique spheres of influence, within a complex 3-dimensional urban structure.
\end{abstract}

\section{Introduction}

A rising global trend of urbanisation is placing mounting pressure on already limited resources such as energy, water and food (THE WORLD BANK, 2012). Urban greenspaces provide a range of services and benefits vital for human physical and mental well-being (COSTANZA 2008). The ecosystem approach and evaluation of ecosystem services allows for consideration of wider ecosystem functionality, offering a holistic perspective of underlying issues critical for efficient management of these natural resources (HAUBECK \& KRONENBERG 2013). This understanding in turn can facilitate comparisons between urban areas, identify neglected areas and assist in policy development (PACIONE 2003). Using remote sensing imagery, vector features and geodemographic datasets, this research addresses knowledge gaps in conceptualisation of 3-dimensional ecosystem multi-functionality through the development of a geographical framework for evaluation of key urban ecosystem services.

\section{Applying a Geographical Context to Ecosystem Services}

Ecosystem services represent more sophisticated ecological measurements than bio-physical landscape factors, as they incorporate human values as well as landscape properties (BURKHARD et al. 2012). However, despite increasing interest in ecosystem service research, the scientific community is still struggling to develop adequate spatial methods for studies finer than national scale (POTSCHIN \& HAINES-YOUNG 2011). The majority of 
current ecosystem service research is conducted assuming a flat 2-dimensional plane, neglecting the 3-dimensional structure of the earth's surface or features such as trees and buildings (NICHOL \& WONG 2005). Furthermore, measurements tend to be directly related to unsuitable land cover/land use maps such as CORINE (EIGENBROD et al. 2011; BURKHARD et al. 2012). Where spatial neighbourhood associations have been considered to determine landscape mosaics (LUCK \& WU 2002), generally only single spatial thresholds are used. These assumptions often result in an over-reliance on unsuitable proxy data and consequently large generalisation, extrapolation and validation errors (EIGENBROD et al. 2011). This research aims to address the spatial knowledge gaps by considering two underlying themes:

1) Urban ecosystem services function and interact in a complex, dynamic 3-dimensional world alongside diverse arrays of human and natural activities and heavily fragmented landscape mosaics (ALBERTI 2005).

2) Building on spatial concepts of ecosystem service units (BURKHARD et al. 2012), this research proposes that overlapping ecosystem service spheres of influence are impacted on by urban structures and are unique to individual services in terms of size and shape. Moreover, these spheres change within services, dependent on neighbourhood associations surrounding their location in the landscape mosaic (RODRIGUEZ et al. 2006).

\section{Study Area}

The study will focus on the city of Salford, located in the metropolitan county of Greater Manchester, United Kingdom. A decline in manufacturing in this region has led to increasing economic and social depression. However, recent creative investment and in particular, the relocation of the British Broadcasting Corporation's (BBC) operations to Salford Quays has promoted large scale investment and regeneration as well as an influx of highly skilled, creative workers, injecting an interesting new demographic into the prior economic and social deprivation experienced by Salford (NOONAN 2012). Salford itself contains a range of land use types including almost $20 \%$ green space as well as urban centres and a large commercial and industrial area near Salford Quays. Management and monitoring of development is critical in ensuring that provision of ecosystem services is available to both workers and the local population.

\section{Building a Spatial Framework}

Through a systematic literature review, six ecosystem services and related environmental indicators required for modelling potential provision have been identified for their general importance in urban areas as outlined in table 1 . These datasets will be validated against secondary data and field survey work before being overlayed to allow classification and characterisation of urban landscape mosaics. Table 1 further indicates that a suitably detailed land cover map is essential in contributing towards ecosystem service measurement. However the intensive heterogeneous nature of urban land cover has traditionally caused problems due to high levels of mixed pixels in medium-resolution imagery and confusion between impervious and soil land covers (XU 2012). To address this problem and to 
create a suitable land cover map, a rule-based approach has been applied to spectral indices derived from Landsat TM imagery to identify bare earth, impervious surfaces, vegetation and water. In concert with the land cover map, the datasets listed in table 1 will be used alongside methods proposed in the literature to develop indicators for each ecosystem service. Where appropriate, spheres of influence representing spatial thresholds will be applied using focal statistics. These will then be combined to produce a novel, integrated map of potential ecosystem service generation to deepen understanding of service trade-offs and synergies through evaluation of overlapping thresholds.

Table 1: Urban ecosystem services

\begin{tabular}{|l|l|l|}
\hline Ecosystem service & Benefits & Datasets required \\
\hline Carbon sequestration & $\begin{array}{l}\text { Air quality regulation, } \\
\text { Carbon storage from pollutants }\end{array}$ & $\begin{array}{l}\text { Tree heights } \\
\text { Land cover/land use }\end{array}$ \\
\hline Water flow regulation & Flood mitigation & $\begin{array}{l}\text { Digital terrain model } \\
\text { Land cover/land use }\end{array}$ \\
\hline $\begin{array}{l}\text { Micro-climate } \\
\text { regulation }\end{array}$ & $\begin{array}{l}\text { Mitigation of urban heat islands and } \\
\text { wind tunnels }\end{array}$ & $\begin{array}{l}\text { Land cover/land use Surface } \\
\text { temperatures } \\
\text { Building and tree heights }\end{array}$ \\
\hline Aesthetics & $\begin{array}{l}\text { Spaces of relaxation } \\
\text { Contact with nature }\end{array}$ & $\begin{array}{l}\text { Noise data } \\
\text { Land cover/land use }\end{array}$ \\
\hline Recreation & Social spaces for exercise & Land cover/land use \\
\hline Habitat services & $\begin{array}{l}\text { Havens for wildlife } \\
\text { Biodiversity protection }\end{array}$ & $\begin{array}{l}\text { Land cover/land use } \\
\text { Biodiversity measurements }\end{array}$ \\
\hline
\end{tabular}

\section{$5 \quad$ Application and Further Research}

A major critique of ecosystem service mapping lies in the broad assumption that if the correct conditions are present, then a service will be provided (MACFAYDEN et al. 2012). However, the presence of consumers is also required for transforming ecosystem properties into ecosystem services. Absolute valuations can be challenging to measure and verify, due to subjectivity and temporal dynamics (COSTANZA 2008). Therefore, service accessibility as a proxy indicator is a useful alternative (BARBOSA et al. 2007). In parallel with the ecosystem service generation framework above, it is anticipated that services have different spatial spheres of attraction or consumption. Consequently, there is scope to apply the framework described above to evaluate ecosystem service accessibilities. These will be developed using a 2-dimensional transport route network, 3-dimensional viewsheds and local population distributions to explore different types of physical and visual accessibility.

The proposed framework allows unique conceptualisation of the 3-dimensional performance of urban ecosystems through an original spatial perspective accounting for spatial thresholds and external influences. Based on overlapping ecosystem service generation and consumption patterns, the framework can further be applied to measurement and mapping of ecosystem service hotspots across a range of urban areas. This provides a deeper understanding through comparison between and within cities, determination of urban quality 
indices, and identification of areas in need of improvement (PACIONE 2003). More specifically it is hoped that in developing a model of accessibilities, an improvement can be made on current guidelines to allow for location-specific development regulations to be put in place, which maintains obtainable standards, while still allowing local character and sense of place to flourish.

\section{References}

AlBERTI, M. (2005), The effects of urban patterns on ecosystem function. International Regional Science Review, 28 (2), 168-192.

Barbosa, O., Tratalos, J. A., Armsworth, P. R., Davies, R. G., Fuller, R. A., Johnson, P. \& GASTON, K. J. (2007), Who benefits from access to green space? A case study from Sheffield, UK. Landscape and Urban Planning, 83 (2-3), 187-195.

Bennett, E. M., Peterson, G. D. \& Gordon, L. J. (2009), Understanding relationships among multiple ecosystem services. Ecology Letters, 12 (12), 1394-1404.

Burkhard, B., Kroll, F., NedKov, S. \& Mueller, F. (2012), Mapping ecosystem service supply, demand and budgets. Ecological Indicators, 21, 17-29.

CostanzA, R. (2008), Ecosystem services: Multiple classification systems are needed. Biological Conservation, 141 (2), 350-352.

Eigenbrod, F., Bell, V. A., Davies, H. N., Heinemeyer, A., Armsworth, P. R. \& GASTON, K. J. (2011), The impact of projected increases in urbanization on ecosystem services. Proceedings of the Royal Society B-Biological Sciences, 278 (1722), 32013208.

HubaceK, K. \& Kronenberg, J. (2013), Synthesizing different perspectives on the value of urban ecosystem services. Landscape and Urban Planning 109 (1), 1-6.

LUCK, M. \& WU, J. G. (2002), A gradient analysis of urban landscape pattern: a case study from the Phoenix metropolitan region, Arizona, USA. Landscape Ecology, 17(4), 327339.

Macfadyen, S., Cunningham, S. A., Costamagna, A. C. \& Schellhorn, N. A. (2012), Managing ecosystem services and biodiversity conservation in agricultural landscapes: are the solutions the same? Journal of Applied Ecology, 49 (3), 690-694.

NiCHOL, J. \& WONG, M. S. (2005). Modeling urban environmental quality in a tropical city. Landscape and Urban Planning, 73 (1), 49-58.

NoONAN, C. (2012), The BBC and decentralisation: the pilgrimage to Manchester. International Journal of Cultural Policy, 18 (4), 363-377.

PACIONE, M. (2003), Urban environmental quality and human wellbeing: A social geographical perspective. Landscape and Urban Planning, 65 (1-2), 19-30.

Potschin, M. B. \& HAINES-Young, R. H. (2011), Ecosystem services: Exploring a geographical perspective. Progress in Physical Geography, 35 (5), 575-594.

Rodriguez, J. P., Beard, T. D., Jr., Bennett, E. M., Cumming, G. S., Cork, S. J., Agard, J., Peterson, G. D. (2006), Trade-offs across space, time, and ecosystem services. Ecology and Society, 11 (1).

THE WORLD BANK (2012), Urban Development. http://data.worldbank.org/topic/urbandevelopment Last accessed $1^{\text {st }}$ October, 2012.

XU, H. (2012), Rule-based impervious surface mapping using high spatial resolution imagery. International Journal of Remote Sensing, 34 (1), 27-44. 